Mathematical Problems of Computer Science 53, 14-20, 2020.

UDC 510.6

\title{
Investigation of Monotonous Properties for Frege Systems
}

\author{
Arsen A. Hambardzumyan \\ Yerevan State University \\ e-mail: arsen.hambardzumyan2@ysumail.am
}

\begin{abstract}
In this paper, we investigate the relations between the Frege proof lines of minimal tautologies and the results of substitutions in them. We show that there is a sequence of tautologies $\psi_{n}$, each of which has a unique minimal tautology $\varphi_{n}$, such that for every $n$ the Frege proof lines of $\varphi_{n}$ are an order more than the Frege proof lines for $\psi_{n}$.

Keywords: Minimal tautology, Frege systems, Proof lines, Monotonous and strong monotonous of proof systems.
\end{abstract}

\section{Introduction}

The minimal tautologies play a main role in the proof complexity area. Really, all propositional formulas, the proof complexities of which are investigated in many well-known papers, are minimal tautologies. There is a traditional assumption that a minimal tautology shouldn't be more complicated than any substitution in it. This idea was first revised by Anikeev in [1]. He introduced the notion of a monotonous proof system and gave examples of monotonous and non-monotonous systems, but both of them are not complete systems. In [2]-[5], the notion of strongly monotonous systems for propositional proof systems is additionally introduced and the properties of monotonous and strongly monotonous for many propositional proof systems of classical and non-classical logics are investigated. Some of the investigated systems (resolution systems, cut-free sequent systems) are monotonous systems, in each of which the proof lines of all minimal tautologies are not more than the proof lines for the results of substitutions in them. Some others are not monotonous (systems based on the splitting method, elimination systems), the proof lines of some substituted formulas in each of which can be less than the proof lines of some corresponding minimal tautologies. It was proved that Frege systems are not strongly monotonous, but the question of monotonicity of Frege systems still remained open. In this paper we prove that Frege systems are not monotonous: it is shown that there is a sequence of tautologies $\psi_{n}$, each of which has a unique minimal tautology $\varphi_{n}$, such that for every $n$ the Frege proof lines of $\varphi_{n}$ are an order more than the Frege proof lines of $\psi_{n}$. 


\section{Preliminaries}

We will use the current concepts of a propositional formula, subformula, elementary subformula, a classical tautology, Frege proof systems for classical propositional logic, proof and proof complexity [1]-[6]. Let us recall some of them.

Definition 1: A Frege system $F$ uses a denumerable set of propositional variables, a finite, complete set of propositional connectives; $F$ has a finite set of inference rules defined by a figure of the form $\frac{A_{1} A_{2} \ldots A_{n}}{B}$ (the rules of inference with zero hypotheses are the axioms

schemes); F must be sound and complete, i.e. for each rule of inference $\frac{A_{1} A_{2} \ldots A_{n}}{B}$ every truth-value assignment, satisfying $A_{1} A_{2} \ldots A_{n}$, also satisfies $B$, and $F$ must prove every tautology.

In the theory of proof complexity, one of the main characteristics of the proof is $t$ complexity, defined as the number of proof steps. Let $\phi$ be a proof system and $\varphi$ be a tautology. We denote by $t_{\varphi}^{\phi}$ the minimal possible value of $t$-complexity for all $\phi$-proofs of the tautology $\varphi$.

Definition 2: Two proof systems are called t-linearly equivalent if any proof in one system can be modified to a proof of the same tautology in another system, so that the t-complexity of the proof is increased not more than linearly.

In [6], it is proved that all Frege systems are $t$-linearly equivalent.

The particular choice of a language for the presented propositional formulas is immaterial in this consideration. However, for some technical reasons we assume that the language contains only logical connectives $\neg, \supset$ and assume that $\vee$ and \& are presented in traditional ways through $\neg, \supset$. We assume that $F$ has the well-known inference rule modus ponens.

By $|\varphi|$ we denote the size of the formula $\varphi$, defined as the number of all logical signs entries in it. It is obvious that the full size of the formula, which is understood to be the number of all symbols, is bounded by some linear function in $|\varphi|$.

Definition 3: A tautology is called minimal if the replacement result of all occurrences for each of its non-elementary subformulas by some new variable is not a tautology.

We denote by $S(\varphi)$ the set of all formulas, every of which is the result of some substitution in a minimal tautology $\varphi$.

Definition 4: The proof system $\phi$ is called $t$-monotonous if for every tautology $\psi$ there is a minimal tautology $\varphi$, such that $\psi \in S(\varphi)$ and $t_{\varphi}^{\phi}=t_{\psi}^{\phi}$.

Definition 5: The proof system $\phi$ is called $t$-strongly monotonous if for every tautology $\psi$ there is no minimal tautology $\varphi$, such that $\psi \in S(\varphi)$ and $t_{\varphi}^{\phi}>t_{\psi}^{\phi}$.

\section{Main Results}

Here we give the main theorem, but first we should give the following auxiliary statements.

Lemma 1: Let $P(A)$ be a tautology, $A$ be some of its subformulas of size $n$, and $P(A)$ not contain $q$. There is a modified image of the subformula $A$ to $A^{\prime}(q)$, and there are not more than $2 n T_{i}(q)$ tautologies that can be proved in a constant number of steps, so that no minimal tautology can be obtained from $P^{\prime}\left(A^{\prime}, q\right)=\left(q \supset P\left(A^{\prime}(q)\right)\right) \& T_{1}(q) \& \ldots \& T_{i}(q) \& \ldots$ tautology by replacing with new variables neither any of the formulas $A^{\prime}(q), T_{1}(q), \ldots, T_{i}(q), \ldots$, nor their non-elementary subformulas. 


\section{Proof:}

Let's describe the modification of each subformula $U$ of $A$, while we will add new conjuncts, i.e., $T_{i}(q)$ s.

1. If $U$ is a variable, then its modification is itself $U^{\prime}=U$. No conjunct will be added.

2. If $U=\left(U_{1} \supset U_{2}\right)$, and q is true $(1)$, then $U$ is equivalent to $\left(U_{1} \supset\left(q \supset U_{2}\right)\right)$. The modified image of $U$ will be $U^{\prime}=\left(U_{1}^{\prime} \supset\left(q \supset U_{2}^{\prime}\right)\right)$, where $U_{1}^{\prime}$ and $U_{2}^{\prime}$ are modified images of $U_{1}$ and $U_{2}$, correspondingly. We will add new conjuncts $\left((\neg q) \supset\left(U_{1}^{\prime} \supset\left(q \supset U_{2}^{\prime}\right)\right)\right)$ and $\left((\neg q) \supset\left(q \supset U_{2}^{\prime}\right)\right)$. If we replace $\left(U_{1}^{\prime} \supset\left(q \supset U_{2}^{\prime}\right)\right)$ in $P^{\prime}$, then $\left((\neg q) \supset\left(U_{1}^{\prime} \supset\left(q \supset U_{2}^{\prime}\right)\right)\right)$ will not remain a tautology. If we replace $\left(q \supset U_{2}^{\prime}\right)$, then $\left((\neg q) \supset\left(q \supset U_{2}^{\prime}\right)\right)$ will not remain a tautology.

3. If $U=\left(\neg U_{1}\right)$, then we should modify $U_{1}$ to $U_{1}^{\prime}$. The modified image of $U$ will be $U^{\prime}=\left(\neg U_{1}^{\prime}\right)$. Then we add $\left(U_{1}^{\prime} \supset\left(\neg\left(\neg U_{1}^{\prime}\right)\right)\right)$ in case $U_{1}^{\prime}$ is a tautology, and $\left(\left(\neg\left(\neg U_{1}^{\prime}\right)\right) \supset U_{1}^{\prime}\right)$ otherwise as a conjunct. If we replace $\left(\neg U_{1}^{\prime}\right)$ or $\left(\neg\left(\neg U_{1}^{\prime}\right)\right)$ in $P^{\prime}$, then the added conjunction won't remain a tautology.

We can replace $U_{1}^{\prime}$ in case of $\neg$, and $U_{1}^{\prime}$ and $U_{2}^{\prime}$ in the case of $\supset$ in added conjuncts, but $P^{\prime}\left(A^{\prime}, q\right)$ won't remain a tautology, because the corresponding conjuncts were added to $P^{\prime}$, which won't allow replacing these formulas. The necessity of the given modifications is presented in Appendix A.

We will add $q \supset$ to $P\left(A^{\prime}(q)\right)$ because we assumed q is true(1) when modifying $\supset$.

So, no minimal can be obtained by replacing any subformula of $A$ or $T_{i}(q)$ in $\left(q \supset P\left(A^{\prime}(q)\right)\right) \& \ldots \& T_{i}(q) \ldots$ Lemma 1 is proved.

Lemma 2: For any formula $A$ of size $n$, there exists a proof of $q \vdash A^{\prime}(q) \supset A$ with $O(n)$ steps.

Proof: For any $\left(U_{1} \supset\left(q \supset U_{2}\right)\right)$

1. $\vdash\left(q \supset\left(\left(U_{1} \supset\left(q \supset U_{2}\right)\right)\right) \supset\left(U_{1} \supset U_{2}\right)\right)$

2. $\vdash\left(\left(U_{1} \supset\left(q \supset U_{2}\right)\right) \supset\left(U_{1} \supset U_{2}\right)\right)$ Modus ponens of premise $q$ and 1.

3. $\vdash\left(q \supset\left(\left(U_{1} \supset U_{2}\right) \supset\left(U_{1} \supset\left(q \supset U_{2}\right)\right)\right)\right)$

4. $\vdash\left(\left(U_{1} \supset U_{2}\right) \supset\left(U_{1} \supset\left(q \supset U_{2}\right)\right)\right)$ Modus ponens of premise $q$ and 3 .

$X_{1} \vdash\left(A^{\prime} \supset A\right)$ from the resulting equivalences using the replacement theorem (Replacement Theorem 6 [7]) and taking into account that the following formulas are tautologies:

$$
\begin{gathered}
\left(\left(D \sim D^{\prime}\right) \supset\left(\left(C \sim C^{\prime}\right) \supset\left((D \supset C) \supset\left(D^{\prime} \supset C^{\prime}\right)\right)\right)\right), \\
\left(\left(D \sim D^{\prime}\right) \supset\left((\neg D) \sim\left(\neg D^{\prime}\right)\right)\right) .
\end{gathered}
$$

Using constant proofs of each of these tautologies and constructing $A$ step by step connecting to two equivalent formulas, not the old ones, but equivalent formulas, $X_{1}=O(n)$. Lemma 2 is proved.

Consider the formula $P=A \vee(p \supset p)$, where $p, q, t, r$ are not present in $A$.

Obviously, $t \vee(p \supset p)$ is minimal of $\mathrm{P}$. If $A$ is a minimal tautology, then $A \vee r$ is also minimal of $P$.

We can construct $P^{\prime}$ applying Lemma 1 to $P$ :

$$
P^{\prime}\left(A^{\prime}(q)\right)=\left(q \supset\left(A^{\prime}(q) \vee(p \supset p)\right)\right) \& \ldots \& T_{i}(q) \& \ldots
$$


It's obvious that $P^{\prime}$ can be proved in $O(n)$ steps and its only minimal is as follows:

$$
M(q, r, A)=\left(q \supset\left(A^{\prime}(q) \vee r\right)\right) \& \ldots \& T_{i}(q) \& \ldots
$$

Suppose it can be proved in $f(n)$ steps. The following three tautologies can be proved in at most $f(n)$ steps.

$$
\begin{gathered}
\left(q \supset\left(A^{\prime}(q) \vee(\neg r)\right)\right) \& \ldots \& T_{i}(q) \& \ldots \\
\left((\neg q) \supset\left(A^{\prime}(\neg q) \vee r\right)\right) \& \ldots \& T_{i}((\neg q)) \& \ldots \\
\left((\neg q) \supset\left(A^{\prime}(\neg q) \vee(\neg r)\right)\right) \& \ldots \& T_{i}((\neg q)) \& \ldots
\end{gathered}
$$

Now we can prove that $t_{A}^{\phi}=O\left(t_{M}^{\phi}+|A|\right)$ for any minimal tautology $A$. To do this, we will use the deduction theorem, which will linearly increase the $t$-complexity of proof. Now we will show $O\left(t_{M}^{\phi}+|A|\right)$ step proof of $(\neg r), q \vdash A$.

$(\neg r), q \vdash$

Step $t_{M}^{\phi}$. $\vdash M$. Using the shortest proof of M from the empty set of premises.

Step $t_{M}^{\phi}+1 . \vdash\left(q \supset\left(A^{\prime} \vee r\right)\right)$. By removing \& in $\mathrm{M}$.

Step $t_{M}^{\phi}+2 . \vdash q$. It's a premise.

Step $t_{M}^{\phi}+3$. $\vdash\left(A^{\prime} \vee r\right)$. Using the modus ponens rule for $t_{M}^{\phi}+2$ and $t_{M}^{\phi}+1$.

Step $t_{M}^{\phi}+4 . \vdash\left((\neg r) \supset\left(A^{\prime} \vee r\right) \supset A^{\prime}\right)$. It's a tautology of form $((\neg r) \supset(a \vee r) \supset a)$

Step $t_{M}^{\phi}+5 . \vdash(\neg r)$. It's a premise.

Step $t_{M}^{\phi}+6 . \vdash\left(\left(A^{\prime} \vee r\right) \supset A^{\prime}\right)$. Using modus ponens for $t_{M}^{\phi}+5$ and $t_{M}^{\phi}+4$.

Step $t_{M}^{\phi}+7$. $\vdash A^{\prime}$. Using modus ponens for $t_{M}^{\phi}+3$ and $t_{M}^{\phi}+6$.

Step $t_{M}^{\phi}+C_{A}$. $\left(A^{\prime} \supset A\right)$. From Lemma 2 .

Step $t_{M}^{\phi}+C_{A}+1$. $A$. Using modus ponens for $t_{M}^{\phi}+7$ and $t_{M}^{\phi}+C_{A}$, where $C_{A}=O(|A|)$ by Lemma 2 .

We can prove the following with the same number of steps:

$$
\begin{gathered}
(\neg r),(\neg q) \vdash\left((\neg q) \supset\left(A^{\prime}(\neg q) \vee r\right)\right) \& \ldots \& T_{i}(\neg q) \& \ldots \\
(\neg(\neg r)), q \vdash\left(q \supset\left(A^{\prime}(q) \vee(\neg r)\right)\right) \& \ldots \& T_{i}(q) \& \ldots \\
(\neg(\neg r)),(\neg q) \vdash\left((\neg q) \supset\left(A^{\prime}(\neg q) \vee(\neg r)\right)\right) \& \ldots \& T_{i}(\neg q) \& \ldots
\end{gathered}
$$

Now, using the deduction rule, we can state that there is an $O(|A|+f(n))$ step proof of the following 4 formulas

$$
\begin{gathered}
(q \supset((\neg r) \supset A)) \\
((\neg q) \supset((\neg r) \supset A)) \\
(q \supset((\neg(\neg r)) \supset A)) \\
((\neg q) \supset((\neg(\neg r)) \supset A))
\end{gathered}
$$

From the first two, we will get $((\neg r) \supset A)$ in a constant number of steps. From the third and forth, we will get $((\neg(\neg r)) \supset A)$ in a constant number of steps. From these two we get $A$ with a constant number of steps. So, we got a proof of $A$ with $O\left(|A|+t_{M}^{\phi}\right)$ steps. Note that the proof of $(q \supset((\neg r) \supset A))$ has been used 4 times.

There exists a sequence of formulas $A_{i}$, such that $t_{A_{i}}^{\phi}=\Omega\left(\frac{\left|A_{i}\right|^{3 / 2}}{\log _{2}^{3}\left(\left|A_{i}\right|\right)}\right)$ by [8]. By the proof above, the following holds $t_{A_{i}}^{\phi}=O\left(\left|A_{i}\right|+t_{M_{i}}^{\phi}\right)$, where $M_{i}$ is the only minimal of $P^{\prime}\left(A_{i}^{\prime}\right)$. 
From the above two estimates we can state that $t_{M_{i}}^{\phi}=\Omega\left(\frac{\left|A_{i}\right|^{3 / 2}}{\log _{2}^{3}\left(\left|A_{i}\right|\right)}\right)$. Using the Lemma 1 , the derivation of $P^{\prime}\left(A_{i}^{\prime}\right)$ is $O\left(\left|A_{i}\right|\right)$. Of these two, we can say that the only minimal of $P^{\prime}\left(A_{i}^{\prime}\right)$ is proved in more steps than the tautology itself for some $i$. Thus, the Frege system $\phi$ is not monotonous.

So, the following was proved:

Theorem 1: Frege systems are not t-monotonous, and consequently, are not t-strongly monotonous.

\section{Conclusion}

We prove, that Frege systems are not $t$-monotonous and, as consequence neither $t$-strongly monotonous. As we state above that all the investigated proof systems are not $t$-strongly monotonous, then the question of the existence of $t$-strongly monotonous systems still remains open.

\section{Acknowledgement}

This work was supported by the RA MES State Committee of Science within the framework of the research project 18T-1B034. I am grateful to my supervisor, professor of YSU Anahit Chubaryan for her encouragement and fruitful discussions, and also for helpful suggestions, which improved and expanded the results.

\section{Appendix A}

Let's show that the modifications in Lemma 1 need to be made in each subformula of $A$, but not only in $A$, in the example of $P(A)=A \vee(p \supset p)$.

Suppose $A=((a \supset b) \supset((\neg b) \supset(\neg a)))$

After the modifications only in the outer implication, the resulting formula will be as follows:

$$
\begin{aligned}
P^{\prime}= & (q \supset((a \supset b) \supset(q \supset((\neg b) \supset(\neg a)))) \vee(p \supset p)) \\
& \&((\neg q) \supset((a \supset b) \supset(q \supset((\neg b) \supset(\neg a))))) \\
& \&((\neg q) \supset(q \supset((\neg b) \supset(\neg a))))
\end{aligned}
$$

Let's replace the formulas $(a \supset b)$ and $((\neg b) \supset(\neg a))$ in $P^{\prime}$ with $t, r$ correspondingly. The resulting formula will be:

$$
\begin{aligned}
M^{\prime}= & (q \supset(t \supset(q \supset r)) \vee(p \supset p)) \\
& \&((\neg q) \supset(t \supset(q \supset r))) \\
& \&((\neg q) \supset(q \supset r))
\end{aligned}
$$

The resulting tautology $M^{\prime}$ is minimal. Thus, $P^{\prime}$ hasn't unique minimal, as stated in theorem. So, the modification in every subformula in formula $A$ is necessary. 


\title{
References
}

[1] А. С. Аникеев, О некоторой классификации выводимых пропозициональных формул, Математические заметки, т. 11, н. 2, сс. 165-174, 1972.

[2] Г. М. Зограбян, С. М. Саядян и А. А. Чубарян, Исследование свойства монотонности некоторых пропозициональных систем выводов классической и неклассических логик, АНАН РА, т. 119, н. 1, сс. 33-39, 2019.

[3] A. Chubaryan, A. Karabakhtsyan and G. Petrosyan, "Some Properties of Several Proof Systems for Intuitionistic, Johanssons and Monotone Propositional Logics", Journal of Asian Scientific Research, vol. 8, no. 2, pp. 61-72, 2018.

[4] А. А. Амбарцумян, Г. А. Гаспарян, С.А. Ованнисян и А. А. Чубарян, О количестве минимальных тавтологий и свойствах их выводов в ряде систем классической и неклассических логик,Математические вопросы кибернетики и вычеслительной техники, т. 52, сс. 66-73, 2019.

[5] A. A. Чубарян, А. А. Амбарцумян, Г. А. Гаспарян и С.А. Ованнисян, О некоторых свойствах минимальных тавтологий классической и неклассических логик, Аоклады НАН РА, т. 120, н. 1, сс. 4-5, 2020.

[6] S. A. Cook and R. A.Reckhow, "The relative efficiency of propositional proof systems", The journal of symbolic logic, vol. 44, no. 1, pp. 36-50, 1979.

[7] S. C. Kleene, Introduction to Metamathematics, Van Nostrand New York, 1952.

[8] A. A. Chubaryan, H. A. Tamazyan and A. S. Tshitoyan, "Some improvement of lower bounds for steps and sizes of proofs in frege systems", Sciences of Europe, vol. 1, no. 37, pp. 39-44, 2019.

Submitted 18.03.2020, accepted 26.06.2020.

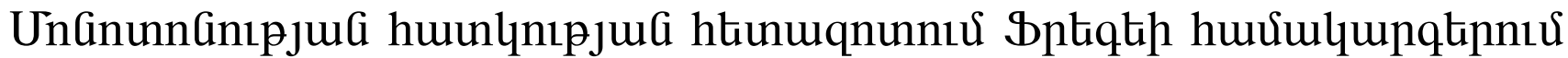

\author{
Unutị U. ¿uựpunánıưjuai

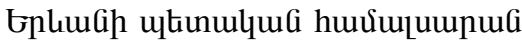 \\ e-mail: hambardzumyanarsen99@gmail.com
}

\section{Uựnnนnıu}

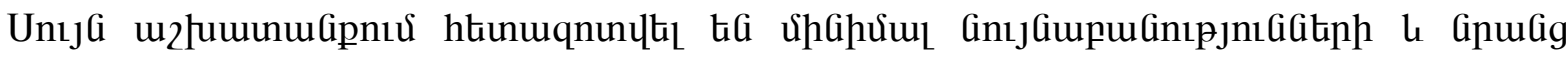

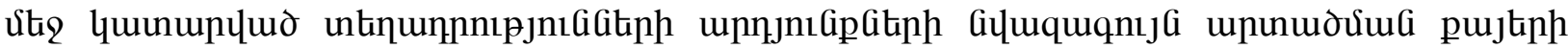

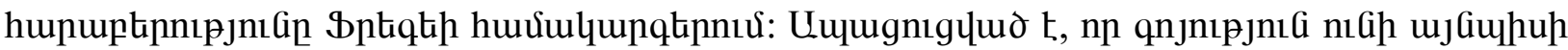

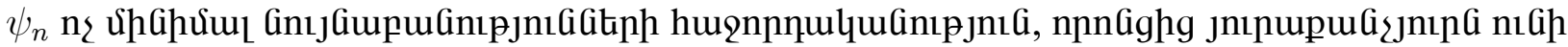

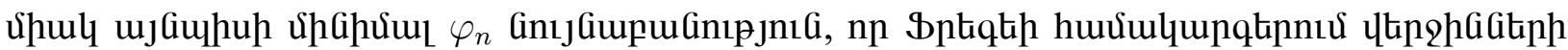

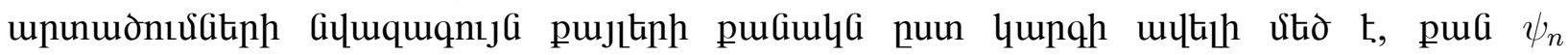

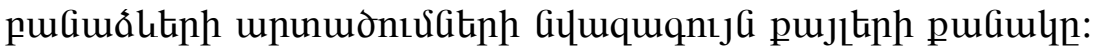

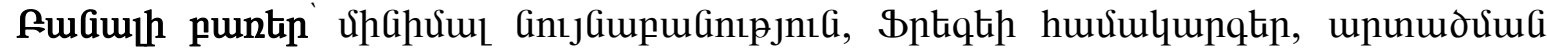

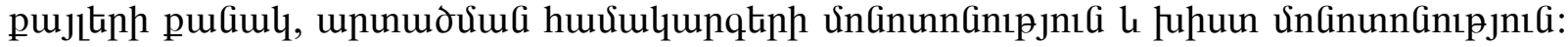




\title{
Исследование свойства монотонности систем Фреге
}

\author{
Арсен А. Амбарцумян \\ Ереванский государственный университет \\ e-mail: hambardzumyanarsen99@gmail.com
}

\begin{abstract}
Аннотация
В настоящей работе для систем Фреге исследовано соотношение количества шагов выводов минимальных тавтологий и результатов подстановки в них. Аоказано, что существует такая последовательность неминимальных тавтологий $\psi_{n}$, каждая из которых имеет единственную минимальную $\varphi_{n}$ и для каждого $n$ количество минимальных шагов выводов в системах Фреге формул $\varphi_{n}$ на порядок больше количества минимальных шагов выводов в системах Фреге формул $\psi_{n}$.

Ключевые слова: минимальная тавтология, системы Фреге, количество шагов выводов, монотонность и строгая монотонность систем выводов.
\end{abstract}

